\title{
Identify the Impact of ICTs in Secondary School Education Students in Government and Private Schools
}

\author{
${ }^{1}$ Singh Shilpa, ${ }^{2}$ Mishra Sunita \\ ${ }^{1}$ M.Phil. Student, ${ }^{2}$ Professor (Dean \& Head) \\ Department of Human Development \& Family Studies
}

School for Home Sciences, Babasaheb Bhimrao Ambedkar University, Lucknow, Uttar Pradesh, India

Abstract-- ICTs provides-motivation to learn. ICTs such as videos, television and multimedia computer software that combine text, sound, and colourful moving images can be used to provide challenging and authentic content that will engage the student in the learning process. Technology is a tool that can provide another way for children to learn and make sense of their world. ICTs play a fundamental and crucial role in teaching learning process at secondary class level. It makes teaching learning process more effective and successful. The usage of ICTs in schools is the implementation of new technologies without having analyzed their appropriateness, applicability and impact on various environments and contexts. The present studies identify the impact of ICTs in secondary school education students in government and private schools. The study was conducted in urban areas of Lucknow city of Uttar Pradesh, in the year 2016. A total of 150 samples which include students and their teachers of secondary level classes selected randomly by government and private schools. Data collected by self made questionnaire which is standardized by specific subject experts. For data analysis $\mathrm{t}$ - test was used in research. The result revealed that impact of ICTs is highly significant on the based on type of schools.

Keywords-- ICTs, ICTs tools, Secondary education, secondary schools, Impact

\section{INTRODUCTION}

ICT used like a general to specific equipment in the schools. Through to education people able to know all around the world at a place. ICTs provided a multitude of possibilities, for not only teaching and learning, for managerial and administrative tasks, for communication, for entertainment. ICTs as a critical tool for preparing and educating students with the require skills for the global work place. (Ibe-Bassey, 2011) ICT is a diverse set of technological tools and resources used to communicate, and manage information. (Adomi \& Kpangban, 2010) Information and Communication Technologies defined as all devices, tools, content, resources, forums, and services, digital and those that can be converted into or delivered through digital forms, which can be deployed for realizing the goals of teaching learning, enhancing access to and reach of resources, building of capacities, as well as management of the educational system. (National Policy on Information and Communication Technology (ICTs) in school education, MHRD, 2012) Major elements of multimedia include text, video, sound, graphics, and animation. These all elements used in ICTs for secondary level students learning. Multimedia simply combines these elements into a powerful new tool; text has the most impact on the quality of the multimedia interaction. Generally, text provides the important information. Text acts as the keystone tying all of the other media elements together; sound is used to provide emphasis or highlight a transition from one page to another. Sound synchronized to screen display, enables teachers to present lots of information at once. Sound used creatively, becomes a stimulus to the imagination; used inappropriately it becomes a hindrance or an annoyance; video represent information by using the visualization capabilities. While this is not in doubt, it is the ability to choose how we view, and interact, with the content of digital video that provides new 
and exciting possibilities for the use of digital video in education. (Singh \& Mishra, 2013)

ICT can be defined as "any object which allows us to get information to communicate with each other or to have an effect on the environment using electronic or digital equipment". (Singh \& Mishra, 2016) Secondary school education comprises of two years of lower secondary and two years of higher secondary education. The lower secondary level is for students aged 14 to 16years. Admission requirement is the completion of upper primary school education. Instruction is more organized along specific subjects. The potentials of information and communication technology (ICT) to facilitate students' learning, improve teaching and enhance institutional administration had been established in literature. ICT improves the learning process through the provision of more interactive educational materials that increase learner's motivation and facilitate the easy acquisition of basic skills. In Primary and Secondary level the use of various multimedia devices such as computer application, OHP, videos, television etc. (Patra, 2014) There is a general lack of awareness about the utility of ICT in education, as well as about the ICT at our disposal and how they can be accessed and utilized economically and effectively. This lack of awareness and knowledge about ICT and their use in education, even on the part of policy makers, administrators and educators, makes it particularly difficult to deploy ICT in the field of school education. Successful integration of ICT in the school system depends largely on the competence and on the attitude of teachers towards the role of modern technologies in teaching and learning. (Kyriakidou \& et al., 2000)

\section{OBJECTIVE}

To identify negative impact of ICT in secondary education students in government and private schools

\section{HYPOTHESIS}

No significant differences showed in impact of ICT in secondary education students in government and private schools.

\section{RESEARCH METHODOLOGY}

The study was conducted in urban areas of Lucknow city of Uttar Pradesh, in the year 2016. Research design followed in the study is cross sectional design. Determine the sample with the use of simple random sampling student is who aged between 14-18 years and studied in secondary education and teachers who are currently teaching ICTs in secondary education schools. The sample size was 150 . Used self made questionnaire which is standardized by specific subject experts for data collection. After data collection, the data were tabulated in Microsoft excel and analysis was done by using frequency, percentage and f-test through SPSS ( $20^{\text {th }}$ version).

\section{RESULT}

Table 1: Mean, SD \& t- Value of impact of ICT in secondary education students in government and private schools:

\begin{tabular}{|c|c|c|c|c|c|c|}
\hline \multirow[t]{2}{*}{ Variable } & \multicolumn{2}{|c|}{ Government } & \multicolumn{2}{|c|}{ Private } & \multirow[t]{2}{*}{ T- value } & \multirow[t]{2}{*}{ Sig. } \\
\hline & Mean & $\mathrm{SD}$ & Mean & SD & & \\
\hline Develops physical problems & 1.06 & .240 & 1.46 & .503 & 159.620 & $.000 * * *$ \\
\hline Increases internet dependency & 1.05 & .221 & 1.43 & .500 & 204.916 & $.000 * * *$ \\
\hline $\begin{array}{l}\text { Negatively affects personality of } \\
\text { students }\end{array}$ & 1.52 & .505 & 1.32 & .471 & 7.018 & $.009 *$ \\
\hline Creates confusion sometimes & 1.92 & .274 & 1.88 & .328 & 1.777 & .186 \\
\hline
\end{tabular}

$\left(\mathrm{p}<0.05^{*}\right) \&(\mathrm{P}<0.001 * * *)$ 


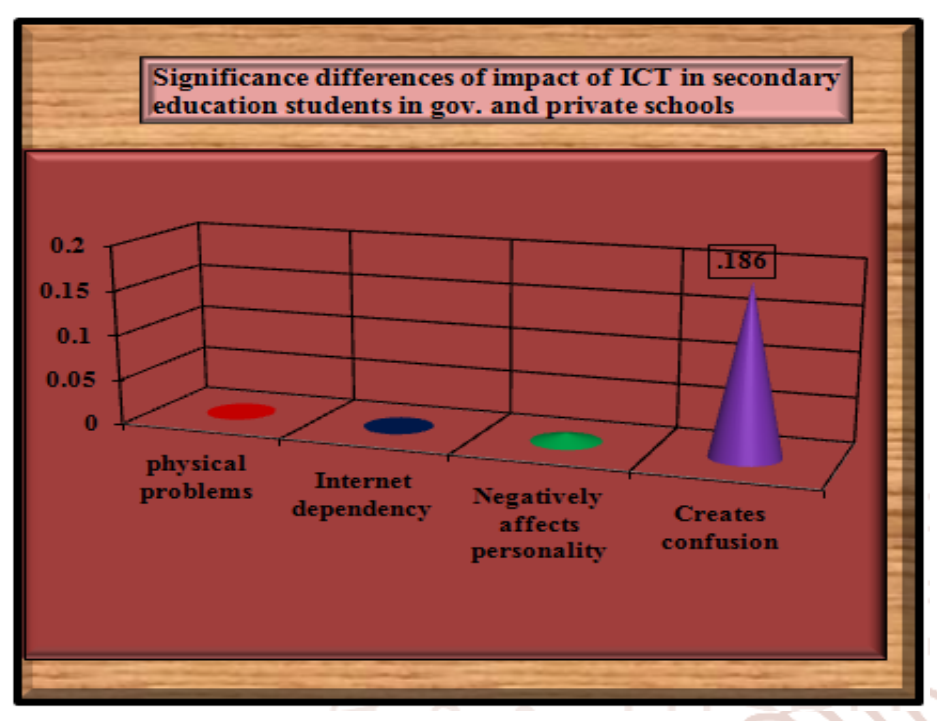

Figure 1: Significance differences of impact of ICT in secondary education students in government and private schools.

The table and figure shown high significance difference in develops physical problems and increases internet dependency. Significance differences shown in negatively affect personality of students whereas no significance difference shown in creates confusion sometime

\section{CONCLUSION}

The major finding of this research is that negative impact having ICT such as physical problems. ICTs stools increase dependency on internet, online teaching, specific software/ application. Students become confusing about content, pictures, videos and situation. This shows that there is an association between dependent and independent variables. The hypothesis was, therefore, not accepted.

\section{References}

[1] Bandyopadhyay, A. (2013). "Technology integration before student outcomes: factors affecting teacher adoption of technology in India", Faculty of the Graduate School of the University of Maryland, College Park, Maryland.

[2] Chandra, R. (2003). "Information technology a revolutionary change", Kalpaz Publication, Delhi, 9. $1-12$

[3] Ibe- Bassey, G. S. (2011). " Human capacity building for information and communication technology ICT integration in teacher education
Nigeria association of educational media and technology (NAEMT).

[4] Adomi, E. E. \& Kpangbon, I. (2010). "Application of ICT's in Nigeria secondary schools", Library philosophy and practice (ejournal), 1-8.

[5] Govt. Of India. (2009). "National Policy on Information and Communication Technology (ICT) In School Education", Draft version1.5, Department of School Education and Literacy, Ministry of Human Resource developmentinternational Institute for Communication and Development. (2014). "ICT in the classroom for quality education (Strengthening learning and teaching methods in under - resourced schools in developing countries)" Raamweg 5 / 2596 HL The Hague / The Netherlands, Phone: +31 (0)70 $3117311 /$ Fax: +31 (0)70 3117322 .

[6] Singh, S. \& Mishra, S. (2013). "A study about role of multimedia in early childhood education", Lap Lambert Academic Publishing, Germany, ISBN: 978-3-659-47127-8, 1-5. Info@lappublishing.com

[7] Singh, S. \& Mishra, S. (2016). "Positive influence of the multimedia in primary education". The international journal of Indian psychology, 3 (2), 179-183.

[8] Singh, S. \& Mishra, S. (2013). "Impact of multimedia in early childhood education". Journal of management and science, 3(3), 75-80.

[9] Patra, N. J. (2014). "The role of ICT in improving the quality of school education in India", International educational E- journal \{Quarterly\}, III (II), 150-156.www.oiirj.org

[10] Kyriakidou, M. \& et al. (2000). "Primary teachers' attitude to the use of ICT: A comparative study between Cyprus and the UK", Paper presented at the European Conference on Educational Research, Lahti, Finland.

[11] Http://www.government-

fleet.com/article/story/2004/09/part-2-wheredoes-your-data-live-and-how-does-it-travel.aspx 7/2/2016, 8.30pm

[12] Http://searchwindevelopment.techtarget.com/d efinition/Internet 7/2/2016,8.48pm

[13] Http://encyclopedia2.thefreedictionary.com/Te lephone+Network 7/2/2016, 9.10pm 